\section{PCR Detection of Mimivirus}

\section{Didier Raoult, Anthony Levasseur, Bernard La Scola}

Author affiliation: Aix-Marseille Université, Marseille, France

DOI: https://dx.doi.org/10.3201/eid2306.161896

In an epidemiological study, mimivirus was reported as an unlikely cause of human respiratory infections in China. Our analysis revealed the nonsensitivity of the PCR method, which detected less than $10 \%$ of the current known mimivirus. We conclude that epidemiologic studies must use accurate and sensitive laboratory test methods.

$\mathrm{T}$ he article by Zhang et al. (1) reporting the failure to detect mimivirus (Acanthamoeba polyphaga mimivirus) in patients with acute respiratory symptoms was flawed in 2 ways. First, a single mimivirus was detected by PCR but was dismissed by the authors as colonization. Second, and of greater concern, the PCR used by the authors would not detect most known mimiviruses because of primer/probe mismatches. In fact, PCRs used in most mimivirus prevalence studies would fail to detect most mimiviruses, given the extensive genome sequence diversity of these viruses (2).

We evaluated the PCR primers/probes used by Zhang et al. (1) for sequence similarity with 51 mimivirus genomes available in the public domain since March 2016, the date on which the article by Zhang et al. was submitted (3). Our in silico analysis found that none of the 25 genomes available from lineage A and 7 genomes from lineage B were complementary with their primers and probes, and only 5 of 19 lineage $\mathrm{C}$ genomes showed sufficient sequence similarity to permit successful amplification (Table). Overall, the PCR used by these authors would be predicted to detect only $\approx 26 \%$ of lineage $\mathrm{C}$ mimiviruses and $<10 \%$ of published mimivirus genomes overall.

As proposed by Ngounga et al. (4), the great variability across the 3 lineages of mimivirus genomes requires the design of lineage-specific primers to improve PCR sensitivity (4). Until PCRs are improved, mimiviruses might be best detected by metagenomic approaches that have recently seen success in terms of mimivirus detection. For example, mimivirus-like reads have been identified by metagenomics in $1(8 \%)$ of 12 fecal samples from children with acute diarrhea (5); $5(27 \%)$ of 18 prostatic secretion samples from persons with prostatitis (6); all DNA libraries tested from the plasma of patients with hepatitis (7); $0.0018 \%$ of total viral reads from nasopharyngeal samples from 210 patients with respiratory tract symptoms (8); and all tested fecal, mid-vaginal, buccal mucosal, and retroauricular crease samples, with a predominance of mimiviruses in fecal samples reaching $\approx 33 \%$ of the total viral reads (9).

In metagenomics approaches, the number of reads detected and the distribution along the whole viral genome

\begin{tabular}{|c|c|c|}
\hline Lineage A (GenBank accession no.) & Lineage B (GenBank accession no.) & Lineage C (GenBank accession no.) \\
\hline Mimivirus fauteuil (CWKE00000000) & Moumouvirus ochan (CXPE00000000) & Megavirus shan (CWIL00000000) \\
\hline Mimivirus longchamps (CXOV00000000) & Moumouvirus istres (PRJEB9189) & Megavirus montpellier3 (CWIA00000000) \\
\hline Mimivirus marais (PRJEB9199) & Moumouvirus battle49 (CXOS00000000) & Megavirus mont1 (CWIO00000000) \\
\hline Mimivirus lactours (CXOL00000000) & Moumouvirus saoudian (CXOQ00000000) & Megavirus avenue9 (CWHN00000000) \\
\hline Mimivirus PointeRouge1 (CXOW00000000) & Moumouvirus boug1 (PRJEB9190) & Megavirus balcon (PRJEB9194) \\
\hline Mimivirus PointeRouge2 (CXOU00000000) & Moumouvirus goulette (KC008572) & Megavirus ursino (CWJY00000000) \\
\hline Mimivirus T3 (CXOR00000000) & Moumouvirus Monve (JN885994- & Megavirus T1 (CWIB00000000) \\
\hline Mimivirus huitre A06 (CWJT00000000) & JN886001) & Megavirus battle43 (CWHV00000000) \\
\hline Mimivirus amazonia (CWHO00000000) & & Megavirus T4 (CWJR00000000) \\
\hline Mimivirus battle7 (CWJW00000000) & & Megavirus J3 (CWIN00000000) \\
\hline Mimivirus battle19 (CWJX00000000) & & Megavirus T6 (CWJQ00000000) \\
\hline Mimivirus battle27 (CWJS00000000) & & Megavirus chilensis (NC_016072) \\
\hline Mimivirus battle57 (CWJZ00000000) & & Megavirus courdo11 (JX975216) \\
\hline Mimivirus battle66 (CWKA00000000) & & Megavirus Iba† (JX885207) \\
\hline Mimivirus battle83 (CWKG00000000) & & Powai lake megavirus (KU877344) \\
\hline Mimivirus battle86 (CWKD00000000) & & Megavirus terra1 (KF527229) \\
\hline Mimivirus T2 (CXOT00000000) & & Megavirus courdo5 (CWID00000000) \\
\hline Mimivirus battle6 (CWJU00000000) & & Megavirus bus (CWIQ00000000) \\
\hline Mimivirus dakar4 (CWKF00000000) & & Megavirus courdo7 (JN885990- \\
\hline Mimivirus (AY653733) & & JN885993) \\
\hline \multicolumn{3}{|l|}{ Mimivirus Bombay (KU761889) } \\
\hline \multicolumn{3}{|l|}{ Mimivirus terra 2 (PRJNA240235) } \\
\hline \multicolumn{3}{|l|}{ Samba virus (KF959826) } \\
\hline \multicolumn{3}{|l|}{ Mimivirus lentille (AFYC00000000) } \\
\hline Mimivirus urine $†$ & & \\
\hline
\end{tabular}


are essential parameters for viral detection. In practice, the search for mimivirus is complicated by the great genetic variability of the virus and the restricted availability of mimivirus culture systems to a few research laboratories (10). The deficiencies we found in the report by Zhang et al. highlight the need for carefully designed epidemiologic studies using sensitive laboratory test methods to accurately assess mimivirus prevalence and the potential role of mimivirus in human disease.

Dr. Raoult is an Associate Editor of Emerging Infectious Diseases and professor of microbiology at the School of Medicine, Aix-Marseille University, Marseille, France, and is head of the University Hospital Institute Méditerranée Infection in Marseille.

\section{References}

1. Zhang XA, Zhu T, Zhang PH, Li H, Li Y, Liu EM, et al. Lack of mimivirus detection in patients with respiratory disease, China. Emerg Infect Dis. 2016;22:2011-2. http://dx.doi.org/10.3201/ eid2211.160687

2. Colson P, Aherfi S, La Scola B, Raoult D. The role of giant viruses of amoebas in humans. Curr Opin Microbiol. 2016;31:199-208. http://dx.doi.org/10.1016/j.mib.2016.04.012

3. Levasseur A, Bekliz M, Chabrière E, Pontarotti P, La Scola B, Raoult D. MIMIVIRE is a defence system in mimivirus that confers resistance to virophage. Nature. 2016;531:249-52. http://dx.doi.org/10.1038/nature17146

4. Ngounga T, Pagnier I, Reteno DG, Raoult D, La Scola B, Colson P. Real-time PCR systems targeting giant viruses of amoebae and their virophages. Intervirology. 2013;56:413-23. http://dx.doi.org/10.1159/000354563

5. Finkbeiner SR, Allred AF, Tarr PI, Klein EJ, Kirkwood CD, Wang D. Metagenomic analysis of human diarrhea: viral detection and discovery. PLoS Pathog. 2008;4:e1000011. http://dx.doi.org/10.1371/journal.ppat.1000011

6. Smelov V, Bzhalava D, Arroyo Mühr LS, Eklund C, Komyakov B, Gorelov A, et al. Detection of DNA viruses in prostate cancer. Sci Rep. 2016;6:25235. http://dx.doi.org/10.1038/ srep25235

7. Law J, Jovel J, Patterson J, Ford G, O'Keefe S, Wang W, et al. Identification of hepatotropic viruses from plasma using deep sequencing: a next generation diagnostic tool. PLoS One. 2013;8:e60595. http://dx.doi.org/10.1371/journal.pone.0060595

8. Lysholm F, Wetterbom A, Lindau C, Darban H, Bjerkner A, Fahlander K, et al. Characterization of the viral microbiome in patients with severe lower respiratory tract infections, using metagenomic sequencing. PLoS One. 2012;7:e30875. http://dx.doi.org/10.1371/journal.pone.0030875

9. Rampelli S, Soverini M, Turroni S, Quercia S, Biagi E, Brigidi P, et al. ViromeScan: a new tool for metagenomic viral community profiling. BMC Genomics. 2016;17:165. http://dx.doi.org/10.1186/ s12864-016-2446-3

10. Saadi H, Pagnier I, Colson P, Cherif JK, Beji M, Boughalmi M, et al. First isolation of mimivirus in a patient with pneumonia. Clin Infect Dis. 2013;57:e127-34. http://dx.doi.org/10.1093/cid/cit354

Address for correspondence: Didier Raoult, Faculté de Médecine, Université de la Méditerranée, URMITE UMR CNRS 6236 IRD 198, Centre National de Référence, 27 Blvd Jean Moulin, Marseille 13005 CEDEX 05, France; email: didier.raoult@gmail.com

\section{Autochthonous Case of Eosinophilic Meningitis Caused by Angiostrongylus cantonensis, France, 2016}

\author{
Yann Nguyen, Benjamin Rossi, Nicolas Argy, \\ Catherine Baker, Beatrice Nickel, \\ Hanspeter Marti, Virginie Zarrouk, \\ Sandrine Houzé, Bruno Fantin, Agnès Lefort
}

Author affiliations: Hôpital Beaujon, Clichy, France (Y. Nguyen, B. Rossi, C. Baker, V. Zarrouk, B. Fantin, A. Lefort); Hôpital Bichat, Paris, France (N. Argy, S. Houzé); Swiss Tropical and Public Health Institute, Basel, Switzerland (B. Nickel, H. Marti); University of Basel, Basel (B. Nickel, H. Marti)

DOI: https://dx.doi.org/10.3201/eid2306.161999

We report a case of a 54-year-old Moroccan woman living in France diagnosed with eosinophilic meningitis caused by Angiostrongylus cantonensis. Diagnosis was based on clinical symptoms and confirmed by testing of serum and cerebrospinal fluid samples. Physicians should consider the risk for $A$. cantonensis infection outside of endemic areas.

A

ngiostrongylus cantonensis is a rat lungworm that has long been recognized as a cause of eosinophilic meningitis in Southeast Asia, the Pacific Islands, and the Caribbean, where it is endemic (1). Although sporadic imported cases have been described in European travelers (2-5), no autochthonous case of eosinophilic meningitis caused by $A$. cantonensis worms has been reported previously in metropolitan France.

A 54-year-old Moroccan woman was admitted to an emergency ward in Paris in 2016 because of fever and headache lasting 2 weeks. She had a history of type 2 diabetes treated with metformin and did not receive any other medication before the onset of symptoms. She was a pesco-vegetarian and worked as a cleaning woman in an office in Paris. She had taken up residence near Paris in the 1980s and had not traveled out of France since, except for Morocco over 2 years ago.

At admission, her blood pressure was 126/68 mm Hg, and her pulse was regular at 79 beats/min. The physical examination revealed meningeal signs with neck stiffness and photophobia without neurologic localization signs. No other clinical abnormality could be evidenced. Laboratory testing of serum showed a leukocyte count of $12.1 \times 10^{9}$ cells/L (reference range $\left.4.5-11.0 \times 10^{9} / \mathrm{L}\right)$ with $18 \%(2.2$ $\times 10^{9}$ cells/L) eosinophils and a C-reactive protein of 73 $\mathrm{mg} / \mathrm{dL}$ (reference range $0.08-3.1 \mathrm{mg} / \mathrm{L}$ ). Cerebrospinal fluid (CSF) analysis showed a leukocyte count of 950 cells/ $\mu \mathrm{L}$ with $56 \%$ eosinophils, a glucose concentration within reference range at $0.4 \mathrm{~g} / \mathrm{L}$, and an elevated protein level 